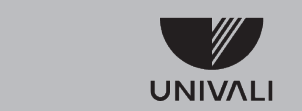

UNIVERSIDADE DO VALE DO ITAJAÍ

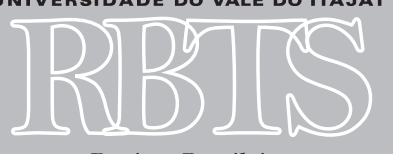

Revista Brasileira de Tecnologias Sociais
1 Assistente Social. Mestre em Gestão de Políticas Públicas (PMGPP/UNIVALI).

2 Antropóloga e Psicóloga. Doutora e Mestre em Antropologia Social (UFSC). Professora do PMGPP/Univali. E-mail:_micheantr@hotmail. com.

\section{A relação público X privado: cofinanciamento da Política de Assistência Social}

\section{The relationship between the public and private sectors: co-financing of the Social Welfare Policy}

\author{
Jaciane Geraldo dos Santos $^{1} \&$ Micheline Ramos de Oliveira ${ }^{2}$
}

RESUMO: Como dever do Estado a política social pública de Assistência Social pode ser assegurada por ação direta do poder público ou pela ação compartilhada com entidades e organizações privadas, sem fins lucrativos. A parceria efetivada entre o poder público e as organizações da sociedade civil atende às demandas sociais, conforme nível de proteção social, através da oferta socioassistencial, pelo repasse de recursos que garantem o custeio parcial a determinadas ofertas. O estudo aborda conceitos para o entendimento das políticas públicas, o papel do Estado como responsável pelo bem comum e o conceito de terceiro setor, com o objetivo de compreender, além da necessidade de sistematização de repasse de recursos às entidades e às organizações da Assistência Social, a forma de relação que se estabeleceu entre o poder público e a sociedade civil organizada. A rede prestadora de serviços socioassistenciais tem papel político importante no fortalecimento do Sistema Único de Assistência Social, com o desafio do gestor público de articular a rede, evitando fragmentações e ofertas desunificadas.

PALAVRAS-CHAVE: Política Pública. Terceiro Setor. Assistência Social. Poder.

ABSTRACT: As a duty of the State, the public social policy of Social Welfare can be provided by direct action of the government or through joint action with private organizations, non-profit organizations and entities. The partnership between the government and civil society meets the social demands, according to the level of social protection, through the offer of social assistance, by the transfer of resources to ensure partial funding to certain offers. The study addresses concepts for understanding public policies, the role of the State as responsible for the common good, and the concept of the third sector, in order to understand the need to systematize the transfer of funds to the Social Welfare entities and organizations, the form of relationship established between the government and organized civil society. The provider of social welfare services has an important political role in strengthening the Sistema Único de Assistência Social [Single Social Welfare System], with the challenge of public managers to articulate the network, avoiding fragmentations and disunited offers. 
KEYWORDS: Public Policy. Third sector. Social welfare. Power.

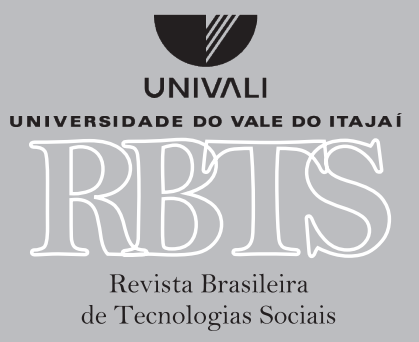




\section{INTRODUÇão}

O Estado não é o único fomentador de políticas sociais públicas, o gestor das necessidades sociais nem sempre se identifica com todas as reivindicações ou simplesmente as ações são insuficientes frente à demanda crescente, assim, a oferta de políticas públicas em nenhum momento foi exclusiva da ação estatal, a sociedade civil organizada não deixou de ofertar estes serviços. Mas, seja de forma direta ou indireta, pelo Estado ou pela sociedade civil organizada, é ele quem tem o poder de decisão, com base nas leis que cria e na implantação de políticas públicas, regulamentando e padronizando as ofertas. Esse padrão deixa em evidência que o Estado detém o poder e sua ação atende aos interesses econômicos dominantes.

O Estado tem a responsabilidade pela normatização, regulação, financiamento, monitoramento e avaliação das organizações das políticas públicas. Na política social pública de Assistência Social, pela Constituição Federal de 1988, uma de suas diretrizes é a descentralização política administrativa, coordenada pela esfera federal e executada pela esfera estadual, municipal, bem como pelas entidades beneficentes e de Assistência Social (BRASIL, 1988).

A Lei Orgânica da Assistência Social atualizada pela Lei No 12.435 de 2011 regulamenta que a gestão das ações na área de Assistência Social fica organizada sob a forma de sistema descentralizado e participativo, denominado Sistema Único de Assistência Social (SUAS), tendo como um de seus objetivos integrar a rede pública e privada de serviços, programas, projetos e benefícios de Assistência Social (BRASIL, 2011 ).

O SUAS é produto de um desenvolvimento anterior no campo assistencial, primeiro pela prática de organizações privadas e depois pela intenção de órgãos públicos criados para este fim. A organização do SUAS requer a articulação entre unidades públicas e entidades ou organizações do terceiro setor por meio da rede socioassistencial. Os serviços, os programas e os projetos desenvolvidos por equipamentos públicos ou privados têm como referência as normativas federais, exigindo um padrão de qualidade como determina a lei, pela provisão de proteção social, sob a hierarquia de proteção básica e especial e ainda por níveis de complexidade.

No presente artigo, apresenta-se a relação público $\mathrm{X}$ privado no cofinanciamento dos serviços socioassistenciais como relação de poder, na tentativa de aprimoramento da parceria com a sociedade civil organizada. A partir deste objeto, discutem-se as políticas públicas, o terceiro setor e na última seção, as relações de poder.

\section{Debatendo políticas públicas}

Política propriamente dita inclui diferentes significados, consciência coletiva para tomada de decisão, a maneira como se organiza e se participa na direção de um determinado assunto, entendida também como ação do governo ou do Estado, conjunto de intervenções para atingir um objetivo. A palavra pública significa o que é de todos ou para todos, sendo assim em prol comum de todos, que difere do que é privado e coletivo. Já a política pública procura aplicar determinados elementos, intervindo em um problema público, buscando solucioná-lo.

Ao se falar em políticas públicas, autores e estudiosos trazem variados conceitos e afirmações. Considerando o tema de estudo, relaciona-se o conceito de política pública como uma ação de iniciativa do Estado, que pode ser executada pelos próprios órgãos governamentais ou pelo terceiro setor, por meio de parcerias; providas e reguladas pelo Estado, mas com a possibilidade de 
serem executadas com as escolhas do setor privado, convertendo ações públicas em decisões privadas que afetam a todos e, por isto, são controladas pela sociedade civil por meio do controle social.

Não há consenso entre os autores sobre os responsáveis pelo planejamento e execução destas políticas públicas. Para alguns, o agente realizador dessas políticas seria o Estado, aplicando um conjunto de medidas isoladas para efetividade dos direitos fundamentais, nessa perspectiva, as políticas públicas só possuem legitimidade se forem governamentais, tratando de iniciativas do poder público. Para outros autores, porém, atualmente, o Estado não é o único fomentador de políticas públicas, dada a importância dos atores privados que buscam propostas e respostas diferentes às demandas sociais.

A sociedade civil vem cada vez mais se organizando para execução e implementação das etapas que constituem uma política pública, além disso, a sociedade civil também vem atuando na fiscalização e na deliberação de políticas públicas por meio da participação nos Conselhos Municipais, Estaduais e Federais.

Há autores que defendem a presença do setor público e o privado em suas definições sobre políticas públicas, como é o caso de Colombarolli (2006, p.178 apud SOUSA; COURA, 2008, p. 8), o qual definiu políticas públicas como "medidas tomadas pelo Estado e/ou pela sociedade civil como o escopo de, legitimamente, efetivarem direitos”.

Assim, a elaboração da política pública está na personalidade jurídica do ator que fomenta, que pode ser tanto o Estado quanto a sociedade civil organizada, desde que haja uma necessidade e objetivos específicos, sejam econômicos, sociais ou políticos para intervir nessa necessidade com ideias desenhadas. A execução da política pública acontece também pela sociedade civil, uma vez que o Estado não consegue suprir funções que lhe cabe, como a função de implantar políticas públicas, em função da ofensiva neoliberal ${ }^{1}$.

Independentemente de quem fomenta a política pública, seja por meio de serviços públicos ou serviços de relevância pública, o Estado e a sociedade civil organizada devem estar de acordo com o ordenamento jurídico do Estado. Assim explica Dye (1972 apud HOWLETT; RASMESH; PERL, 2013) que o agente primário da policy-making pública é o governo, este tem papel especial por força da sua capacidade de tomar decisões oficiais em nome dos cidadãos, isto é, decisões sustentadas por sanções contra quem as transgredir.

Nessa perspectiva o Estado é o formulador da política pública, é ele quem define a primeira etapa da implantação de um conjunto de decisões que delimitam a política pública, uma vez que ele é instância de formulação da legislação, dos atos, das regulamentações oficiais. Lowi (1972 apud SECHI 2012, p. 15) afirma que "a política pública determina a política”, pois tudo que o governo faz ou deixa de fazer para garantia de direitos da sociedade, os impactos de suas ações e de sua negligência são uma decisão mediante jogo de interesses, de relações de poder que estruturam as condições de vida dos grupos sociais, criadas e mantidas pelo Estado.

Para concretização dos direitos que estão constitucionalmente garantidos, o Estado implanta e implementa as políticas públicas. Mas não só a Constituição Federal, que garante direito, também é preciso criar políticas públicas, cumpridos os direitos humanos, sociais, ambientais, etc., os quais são garantidos nas Constituições Estaduais e Leis Orgânicas Municipais.

Exemplificando, a Constituição Federal de 1988 coloca que:

1 Que se intensifica no país a partir da década de 90, que reduz o papel do Estado e com isso o financiamento em políticas sociais e estimula a parceria público-privado. 
Art. 203. A assistência social será prestada a quem dela necessitar, independentemente de contribuição à seguridade social, e tem por objetivos:

I - a proteção à família, à maternidade, à infância, à adolescência e à velhice;

II - o amparo às crianças e adolescentes carentes;

III - a promoção da integração ao mercado de trabalho;

IV - a habilitação e reabilitação das pessoas portadoras de deficiência e a promoção de sua integração à vida comunitária;

V - a garantia de um salário mínimo de benefício mensal à pessoa portadora de deficiência e ao idoso que comprovem não possuir meios de prover à própria manutenção ou de tê-la provida por sua família, conforme dispuser a lei. (BRASIL, 1988)

Não basta a garantia deste direito por meio da Carta Magna, sua prática se efetiva a partir da implantação e da execução da política pública de Assistência Social.

A política de Assistência Social se efetivou vagorosamente por agentes públicos e privados. Essa política, quando regulamentada e formulada através de um texto legal, veio sofrendo impactos e mudanças na sua operacionalização, uma vez que, anteriormente, cada agente executava à sua maneira.

A trajetória da Assistência Social no Brasil tem características de ações tradicionalmente paternalistas e clientelistas do Poder Público, associadas às primeiras damas, com um caráter de benesse, tendo o usuário como assistido e favorecido e nunca como cidadão de direitos. Este legado de práticas assistencialistas foi sempre apropriado pelo Estado e direcionado à sociedade civil, seja pela solidariedade da igreja ou por segmentos da elite brasileira. Somente a partir da CF/88 que a política de Assistência Social se configura como política pública de responsabilidade estatal e direito do cidadão.

Foram sendo formuladas estratégias pelo Estado à solução de problemas relacionados às vulnerabilidades e às mazelas sociais para obtenção de maiores níveis de bem-estar-social da sociedade, garantindo os mínimos sociais a quem necessitar. Estabelecidos os meios e os objetivos, a política se direciona e os agentes, públicos e privados, entram em ação, concretizando os direitos da sociedade.

Um aspecto fundamental que deve ser considerado nestas discussões é que nenhum agente terá condições de implementar determinada política se não planejar e definir quais e quantos recursos serão utilizados. Não basta que a política pública seja uma ferramenta utilizada pelos governos para atingir objetivos com determinados fins e metas colocadas, é necessário critério, linha de ação, previsão orçamentária, recursos humanos e materiais. Como diz Dias e Matos (2012), a eficiência é o aspecto-chave da boa formulação da política pública, é a capacidade de o Estado alocar seus recursos escassos às atividades em que eles tenham os maiores retornos, que assegure retornos sociais elevados.

A eficiência é imprescindível e sem ela nenhuma política pública poderá ser realizada. Trata-se de um processo de provisão, distribuição e aplicação dos recursos necessários à execução, o qual deve ser realizado de maneira transparente com prestação de contas, anuência da sociedade e respeitando a diversidade das regiões abrangidas. "O financiamento ocorre de escolhas, preferências e decisões tomadas pelos agentes políticos, e para realização de qualquer política pública, a alocação de recursos públicos é fator determinante” (BRANDÃO, 2012, p. 3). 
No caso da política de Assistência Social, o financiamento é disposto na Constituição Federal, na Lei Orgânica da Assistência Social (LOAS) e na Norma Operacional Básica (NOB/ SUAS), mas antes da CF o financiamento acontecia de forma diferente. Para Brandão (2012, p.4):

Os serviços de Assistência Social eram fornecidos pelas entidades filantrópicas até o fim da II Guerra Mundial onde tais serviços passaram a ser institucionalizados nas Organizações Não Governamentais. Na década de 80 entidades filantrópicas e grupos organizados de ONG's se organizaram para lançamentos de Programas de abrangência Nacional, recebendo subvenções do governo federal, seu principal financiador.

Estes grupos organizados em associações defendiam a implementação de proteção social por meio de subsetores, como rede de creches, idosos, pessoas com deficiência, sendo que a estrutura desta organização resultou em movimentos sociais. Com a força dos Movimentos Sociais sobre a "Assembleia Constituinte", a Assistência Social teve sua definição como política de seguridade social juntamente com a saúde e a previdência social. O Estado passou a ter a responsabilidade pela elaboração e pela coordenação das normas gerais; e as organizações de natureza público-privada, por meio das entidades beneficentes e de Assistência Social, passaram a exercer programas e ações simultaneamente às condições do Estado.

Prega a Constituição Federal que a seguridade social deve ser financiada por toda a sociedade, com recursos provenientes da União, dos Estados, do Distrito Federal e dos Municípios. Consta na LOAS que o financiamento da Assistência Social deve ser realizado com recursos aportados no Fundo Nacional de Assistência Social; e as transferências de recursos da União, Estados, Distrito Federal e Municípios devem ser feitas mediante prévia comprovação da efetividade institucional e funcional de Conselho, Plano e Fundo. Pela diretriz da descentralização político administrativa, os municípios, como entes federados, têm também a responsabilidade pela prestação de serviços, programas, projetos e benefícios.

Na década de 1990, o movimento da participação da esfera privada na execução das políticas sociais ganhou densidade específica, impulsionado por um amplo projeto da esfera privada na execução de reforma de Estado que pleiteava a ação pública assentada na reforma do Estado e em uma ação de cooperação entre ele e a sociedade na implementação das políticas sociais.

O financiamento passa a ser uma responsabilidade conjunta dos entes federados, porém, na prática, continua a ser realizado por meio de convênios firmados entre os entes federados ou destes com entidades filantrópicas e ONG'S. Assim, antes de 1993 e anos posteriores, o financiamento do orçamento federal à Assistência Social foi destinado às ações desarticuladas, entregues a diferentes órgãos, programas e projetos que não coadunavam com o estabelecido na LOAS, as ações que quando recebiam recursos transitavam fora do fundo.

Quando a LOAS buscou sistematizar o processo, previu a superação de um legado de poucos recursos, ações pontuais e baixa capacidade técnica. Todo reordenamento institucional da área previu e privilegiou o corte de gastos e redução do deficit público, assim diz Lima (2003 apud BRANDÃO, 2012, p.8).

A LOAS trouxe um capítulo específico, buscando regulamentar o financiamento da política de Assistência Social, estabelecendo critérios e procedimentos relativos ao repasse de recursos financeiros aos municípios, destinados à expansão dos serviços socioassistenciais, definiu normas e procedimentos à celebração de convênios e instrumentos congêneres, diretamente relacionadas 
ao financiamento entre os três entes federados e, sobretudo, o repasse fundo a fundo do governo federal aos municípios.

Até o início dos anos 2000, a política pública de Assistência Social ainda permanecia marcada por uma precária atuação do Estado na oferta de serviços socioassistenciais. A configuração desarticulada repercutia no financiamento não apenas quanto às iniciativas públicas, como também em uma complexa institucionalidade no aporte de recursos às entidades privadas.

Com a implantação do SUAS, a partir de 2004 e 2005, através da PNAS, um novo formato se firmou e um dos eixos estruturantes da gestão do SUAS é o "financiamento partilhado entre a União, os Estados, o Distrito Federal e os Municípios” (CNAS, 2004).

Por ter como uma de suas bases o financiamento, reforça a responsabilidade comum dos três entes federados, assegurando o financiamento partilhado entre União, Estados e Municípios, por meio de transferências fundo a fundo ou por aporte de recursos próprios. O financiamento deve estar em consonância com o caráter das ofertas do SUAS, visto serem continuado e descentralizado, não se concebe mais um financiamento pautado em formas tradicionais, convenial.

Operacionalizando o que a Política Nacional regulamentou em 2004, a Norma Operacional Básica, aprovada em 2005 e reformulada em 2012, traz como um dos objetivos do SUAS “consolidar a gestão compartilhada, o cofinanciamento e a cooperação técnica entre a União, os Estados, o Distrito Federal e os Municípios que, de modo articulado, operam a proteção social não contributiva e garantem os direitos dos usuários" (CNAS, 2012).

A partir desta norma, a gestão financeira e orçamentária do SUAS trouxe os seguintes instrumentos: orçamento, que expressa o planejamento financeiro da assistência social; fundos de Assistência: unidades orçamentárias e gestoras dos recursos alocados e executados; e cofinanciamento: financiamento compartilhado por meio de transferências regulares e automáticas entre fundos (CNAS, 2012).

O SUAS inaugura uma nova lógica de financiamento para esta política pública, pautada no reconhecimento de que as ações se efetivam, de forma descentralizada, nos espaços locais, conforme a demanda do município, a partir de um diagnóstico apresentado, com custeio para ações e serviços de caráter continuado.

A Política Nacional de Assistência Social e a Norma Operacional Básica trouxeram uma nova articulação visando à efetivação da Política Pública. O escopo da política passa a ter a família como foco principal do atendimento, até então organizada em função de segmentos. Outra mudança foi que a política deveria afiançar sua organização em níveis de proteção, básica e especial. O financiamento passou a operar com a coparticipação dos entes federados na efetivação das provisões afetas a esta política. O fundo de Assistência Social foi reforçado como instância privilegiada de seu financiamento. A forma inovadora de financiamento do SUAS busca estabelecer relação organizada entre gestão, controle social e entes financiados, mas não regulamenta a transferência de recursos às entidades.

O repasse de recurso às entidades foi uma prática não sistematizada pelas legislações vigentes, apenas como prática do ente federado municipal que utilizava o repasse para beneficiar algumas entidades em decorrência da influência política, conforme o interesse e as relações de poder estabelecidas com quem prestava o serviço, não buscando atender à realidade do município, mas a prática institucionalizada. 
Desde 1993, com a regulamentação da LOAS e posteriormente com a Lei N ${ }^{\circ}$ 12.435/201 1 que altera a organização da Assistência Social, lei do SUAS, não foi normatizado o repasse de recursos à rede socioassistencial privada. Entretanto, a parceria sempre foi formalizada para atender às necessidades de bens e serviços em determinadas áreas.

Pelas crescentes demandas sociais e exigências à garantia de direitos, o Estado utiliza a alternativa de parcerias para melhorar seu desempenho, dividindo sua função com as organizações da sociedade civil. As parcerias podem ser estabelecidas por meio de contratos de gestão, termos de parcerias, consórcios, convênio, dentre outros diferentes instrumentos que formalizavam a relação do poder público com as organizações. O terceiro setor, setor público não estatal, assume esta parceria como de responsabilidade pública também devido à necessidade de maior captação de recursos.

Diante da falta de regulamentação da relação entre público e privado, não só para política de Assistência Social, mas para toda e qualquer política pública, uma agenda foi construída com avanços significativos e em 2014 foi aprovada a Lei $N^{\circ}$ 13.019/2014. Com ela uma nova relação começa a ser implantada na parceria com o Estado e a sociedade civil organizada por meio de fomento e colaboração, que se torna o marco regulatório das organizações da sociedade civil. A lei foi construída de forma democrática e participativa por representantes de órgãos federais e organizações da sociedade civil (MROSC, 2014) ${ }^{2}$.

A supracitada lei surge para aperfeiçoar o ambiente jurídico e institucional relacionado às organizações da sociedade civil e às suas relações ou parcerias com o Estado, buscando segurança jurídica, valorizações das organizações da sociedade civil, transparência na aplicação dos recursos e efetividade nas parcerias (MROSC, 2014).

Por não haver regulamentação específica, as interpretações eram distintas e pouca ênfase era dada ao controle dos resultados e, principalmente, ao estoque de prestações de contas. A lei veio para estabelecer o regime jurídico das parcerias voluntárias, envolvendo ou não transferências de recursos financeiros entre a administração pública e as organizações da sociedade civil em regime de mútua cooperação, para a consecução de finalidades de interesse público. Ela define diretrizes para a política de fomento e de colaboração com organizações da sociedade civil; institui o termo de colaboração e o termo de fomento, instrumento jurídico próprio da relação entre estado e sociedade civil. Será o fim dos convênios para as organizações da sociedade civil.

A atuação em rede será agregada às ofertas, valorizando a integração entre as organizações da sociedade civil. O chamamento público será obrigatório, dando transparência e democratização do acesso às parcerias com editais. Não será mais permitida a exigência de contrapartida. Deverá ser criada a Comissão de Monitoramento e Avaliação nos órgãos e também será obrigatória a pesquisa junto a beneficiários. Poderá haver a manifestação de interesse social por meio da elaboração de propostas de chamamento público pelas próprias organizações da sociedade civil, movimentos sociais e interessados (MROSC, 2014).

\section{Política Pública X Política Social}

A política pública consiste em diretrizes para enfrentar um problema público, conjunto de objetivos que depois de desenhados e formulados determina um conjunto de ações a serem

2 MROSC. Marco Regulatório das Organizações da Sociedade Civil. Disponível em: http://www.participa.br/osc\#.VXy-Zv9_n6g. Acesso em: 01 maio de 2015. 
implementadas. A política social é produzida sob distintas estruturas legais e institucionais, dentre estas, as ações de governo voltadas para proteção social.

As políticas sociais públicas referem às ações que exercem um impacto sobre o bemestar dos cidadãos. Operacionalizar a Assistência Social como política social pública é sinônimo de trabalhar de forma planejada, executando com equipamentos específicos, com ofertas definidas, conforme mapeamento da realidade social de cada região (SNAS, 2008).

A expressão da cidadania diz respeito aos direitos civis, políticos e sociais. Estes dizem respeito ao bem-estar coletivo e à garantia de um nível mínimo de consumo para todos os cidadãos. Essas conquistas poderão ser atingidas sob pressão ou traduzidas por meio de políticas sociais formuladas e implementadas pelo Estado (AUGUSTO, 1989).

Com o objetivo de ofertar ao cidadão a proteção social, a política social vem para atenuar as mazelas da sociedade, participando da elaboração política de conflitos de classe e da formulação de estratégias ao enfrentamento da crise do processo de acumulação capitalista. "As ações estatais a ela vinculada teriam caráter compensatório e redistributivo e, estando destinadas a proporcionar consumos específicos e encontrando no Estado seu agente privilegiado, são entendidas como importante instrumento de controle dos antagonismos sociais" (SANTOS, 1979; DRAIBE, 1986 apud AUGUSTO, 1989, p.3). Representa, desta forma, a garantia dos mínimos sociais, por meio de renda mínima indireta e complemento aos trabalhadores e a quem necessitar, ou seja, sem condições para seu autossustento.

As políticas sociais são historicamente construídas, reconfiguram-se e desaparecem, de acordo com o desenvolvimento da sociedade, são tanto públicas quanto privadas. Isto porque existem instituições prestadoras de serviços com institucionalidade pública estatal, pública não estatal e privada. Pfeifer (2014) alega que as políticas sociais respondem ao conjunto de necessidades sociais humanas, que são: saúde, educação, inclusão social, previdência, dentre outras.

A política social é um tema que não pode ser estudado de forma isolada, é preciso analisar as políticas econômicas e as expressões da questão social na conjuntura atual. "Como política pública, portanto, a política social deve ser entendida em sua dimensão histórica e política” (VIANNA, 2002, p.1). Conhecer o contexto político e econômico é fundamental para que se compreenda o modo como o Estado realiza a produção e a implementação de determinada política pública. O Estado precisa estar organizado e contar com o apoio de atores sociais para a resolução de problemas societários.

Para implementação de direitos há a limitação burocrática de poder e recursos, domínios estruturados pelas políticas e instituições, por isto os modelos de políticas vão se modificando conforme a lógica do capital. O aumento das demandas da sociedade é crescente e precisa ser atendido. Mas o Estado, antes de efetivar qualquer política pública, seja através de parcerias ou de execução direta, precisa viabilizar recursos, capacitar atores para que se qualifiquem na intervenção a ser realizada.

Ainda que sejam formuladas e implementadas estratégias de enfrentamento às expressões da questão social ${ }^{3}$, essas estratégias vêm ao encontro da reprodução do capital, demonstrando que o desafio é a manutenção de níveis significativos e sustentáveis de crescimento econômico. Os

3 Entende-se a questão social oriunda da relação capital/trabalho, processo de produção e exploração capitalista, que se manifesta pelas desigualdades sociais e que são as expressões da questão social. 
interesses econômicos sobressaem os serviços sociais, justificando-se, pois, pela lógica neoliberal, onde os interesses financeiros afrouxam o desenvolvimento social.

A ação do Estado é disciplinada para o enfrentamento dos problemas sociais sem ameaçar a reprodutividade do capital, significando que sua atuação é limitada à manutenção da ordem social e é determinada pela necessidade de reprodução da base material.

A intervenção na área social vem acontecendo de forma articulada com organizações governamentais e não governamentais. Por mais que o governo formule políticas sociais públicas, é perceptível o crescimento de instituições e agentes privados na efetivação destas políticas, buscando satisfazer ou melhorar as ofertas diante das necessidades sociais. O Estado brasileiro não consegue uma intervenção orgânica das políticas sociais públicas, seja pela particularidade de cada território, pela distância entre a legalidade e a prática ou ainda, pela inexistência ou impossibilidade dos órgãos gestores, municipais, estaduais e federais em assessorar as instituições.

\section{DisCUTINDO O TERCEIRO SETOR}

O Estado é o primeiro setor, representado por órgãos públicos e entes políticos, e quando se fala em Estado, está-se referindo às suas expressões nacional, estadual e municipal. É o governo que representa os bens públicos em prol do interesse público. O Estado detém o monopólio do poder realizado por meio de normatizações jurídicas.

O segundo setor é constituído pelo mercado, empresas que atuam em prol de bens próprios, privados ou particulares e visam ao lucro.

A fusão da relação público-privado nas manifestações da questão social (situações de pobreza, miséria, relações de trabalho, desemprego, precariedade na saúde, educação, etc.) está cada vez mais concreta na conjuntura atual.

A lógica neoliberal ao mesmo tempo em que identifica os problemas sociais como responsabilidade dos indivíduos também sugere que sejam resolvidos no âmbito privado - através de esforços próprios ou, quando isso não é possível, através de instituições privadas da sociedade civil atreladas às práticas de doações e do "trabalho" voluntário. (BONFIM, 2010, p. 272).

Com a intensificação do processo de globalização no final do século XX, os Estados vêm se mostrando cada vez mais incapazes de assegurar uma ordem mundial devido ao aumento dos atores e da complexidade das relações.

As mudanças na sociedade indicam a reestruturação das funções tradicionais do Estado, implicando a incorporação de novos atores do setor público não estatal e privado na implementação de políticas públicas.

Tais mudanças solicitam também alterações na estrutura e nos desenhos das políticas públicas e, consequentemente, na forma de o Estado se relacionar com a sociedade. Dias e Cario (2014, p. 347) dizem que:

O Estado vem ao longo de muitos movimentos de reforma administrativa, reduzindo sua atuação como executor direto de serviços e assumindo o caráter de mobilizador e ativador dos diversos atores, estando no centro das suas funções a capacidade de promoção e coordenação estratégica para o desenvolvimento da sociedade. 
Caracteriza assim, um novo estilo de governo, organizado numa estrutura de rede e não mais centralizado no controle hierárquico, mas por meio do envolvimento e da cooperação de responsabilidades entre o setor público, privado e o terceiro setor. A sociedade civil contribui para efetivar as ações e as condutas propostas.

As organizações não governamentais sem fins lucrativos constituem o terceiro setor e surgem para suprir lacunas, necessidades e anseios da população que o Estado não conseguiu atender pela ampliação de novas demandas não acompanhadas pela estrutura estatal.

A sociedade civil organizada vem assumindo, cada vez mais, responsabilidade na esfera social, por meio de entidades filantrópicas, organizações não governamentais, organizações da sociedade civil, as quais buscam atender às camadas populares mais vulneráveis economicamente, sobretudo, onde a ausência do papel do Estado é mais evidente.

Algumas destas entidades mobilizam-se por meio da participação popular para reivindicação de direitos. A iniciativa da sociedade civil é como uma espécie de conformação da própria sociedade civil com a negligência do Estado em relação aos direitos civis. Assim a sociedade civil assume a responsabilidade ou a parceria do Estado para garantia de direitos universalizados.

Mesmo com o surgimento do terceiro setor e após o aumento das entidades, não exime o governo de suas responsabilidades como Estado, tampouco a do mercado como impulsionador do crescimento e dos investimentos nas responsabilidades sociais. Estas instituições terão atividades complementares, uma parceria que resulta na resolução de problemas sociais.

Contudo Paes (2000, p.88) argumenta que o terceiro setor é definido como "aquele que não é público nem privado, no sentido convencional desses, guarda relação simbiótica com ambos, na medida em que ele deriva sua própria atividade da conjugação entre a metodologia deste com a finalidade daquele”. Isto porque é uma entidade privada, com finalidade pública.

Para Montano (2007), o terceiro setor veio para resolver uma lacuna entre o primeiro e o segundo setor, uma vez que o Estado está em crise e o mercado tem uma lógica lucrativa, quem poderia dar respostas às demandas sociais seria uma atividade desenvolvida pelo público, mas em âmbito privado.

\section{ENTIDADES E ORGANIZAÇÕES DE AsSistêNCIA SOCIAL}

As entidades ou as organizações de Assistência Social devem executar ações de caráter continuado, permanente e planejado, bem como garantir a gratuidade de todos os serviços, programas, projetos e benefícios socioassistenciais, sob a primazia de garantia de direitos do usuário e sua autonomia. Além destas características, deve garantir a existência de processos participativos dos usuários na busca do cumprimento da missão da entidade ou organização.

Todas estas definições são apresentadas no Decreto $\mathrm{N}^{\circ}$ 6.308/2007, na Lei Orgânica da Assistência Social, e estão regulamentadas na Resolução do CNAS No 109/2009, Resolução do CNAS No 27/2011, Resolução do CNAS No 33/2011, Resolução No 34/2011 e Resolução No 14/2014 também do Conselho Nacional de Assistência Social.

As entidades que desenvolvem ações pontuais, esporádicas, distribuição de cestas básicas, refeições, vestuários a famílias carentes de forma eventual e não continuadas ou que exige pagamento dos usuários não se caracterizam como de Assistência Social, pois sua atividade 
constitui-se como caritativa e/ou religiosa, não como prestação de serviço permanente e planejado nos termos da PNAS.

$\mathrm{O}$ artigo $3^{\circ}$ da LOAS, revisado pela Lei $\mathrm{N}^{\circ} 12.435 / 2011$, regulamenta as características fundamentais das entidades socioassistenciais, como garantir a universalidade do atendimento, independente da contribuição do usuário, possuindo finalidade pública e transparências nas ações, devendo suas ações ser executadas de forma permanente, planejada e continuada. Pelo referido artigo, as entidades e as organizações de assistência social são aquelas sem fins lucrativos, que isolada ou cumulativamente prestam atendimento, assessoramento ou que atuam na defesa e na garantia de direitos (BRASIL, 2011).

Esta reorganização faz-se necessária para adequação de critérios e normas para as entidades socioassistenciais na sua vinculação com o SUAS, possibilitando o controle no cadastramento das entidades e dos serviços que prestam aos usuários da Política de Assistência Social.

As entidades ou as rganizações de Assistência Social podem, isoladas ou cumulativamente, ser de atendimento - aquelas de forma continuada, permanente e planejada, prestam serviços, executam programas ou projetos e concedem benefícios na proteção básica ou especial, dirigidas às famílias e indivíduos em situação de vulnerabilidade ou risco social e pessoal; de assessoramento, aquelas de forma continuada, permanente e planejada, prestam serviços e executam programas ou projetos voltados prioritariamente para o fortalecimento dos movimentos sociais e das organizações de usuários, formação e capacitação de lideranças, dirigidas ao público de assistência social; de defesa e garantia de direitos, aquelas de forma continuada, permanente e planejada, prestam serviços e executam programas e projetos voltados prioritariamente para defesa e efetivação dos direitos socioassistenciais, construção de novos direitos, promoção de cidadania, enfrentamento das desigualdades sociais, articulação com órgãos públicos de defesa de direitos, dirigidos ao público da política de assistência social (CNAS, 2014).

Esta caraterização aponta uma série de desafios, fazendo com que a implementação e a estruturação de serviços sejam capazes de realizar intervenções sólidas, efetivas e continuadas, rompendo com o caráter imediatista e encaminhador, sem acompanhamento ou retorno sobre a qualidade dos serviços socioassistenciais e atendimentos ofertados.

As entidades têm resistência à mudança, pois sua prática se institucionalizou e criou grupos de interessados na sua perpetuação. No caso da Política de Assistência Social, a trajetória desprovida de racionalidade técnica e política deixou um legado de práticas imediatistas, sedimentadas na ajuda, na filantropia e no clientelismo. Sendo assim, as mudanças debatidas que deveriam ser incorporadas em todos os níveis da federação são lentas e graduais.

Dependendo do contex to econômico e político e do movimento de pressão e negociação, as relações de poder permanecem. Este processo é contraditório e requer a coordenação do Estado, que precisa coalizar políticas capazes de referenciar as entidades sociais, reordenando as decisões, a elaboração e a implementação, as quais influenciam nos resultados e nos conflitos inerentes às decisões sobre política públicas.

O terceiro setor tem caráter estratégico no âmbito de qualquer sociedade que se preocupe com o desenvolvimento social, comprometido com a solidariedade humana e o sentimento de comunidade. Para Paes (2000), no Brasil, apesar da forte presença do Estado, a ineficiência deste abre espaço para muitas outras iniciativas. Assumem responsabilidades que são do Estado, mas incorporam valores que são próprios. 
Ainda diante do reordenamento da Política Pública de Assistência Social, as atividades e as finalidades enraizadas permanecem nas ofertas. Há que se destacar que a política é um processo histórico, não linear, sempre em movimento, que, neste processo, vira mutação, escolha que nem sempre é coerente com as mudanças que se almejam, mas com o processo histórico que se construiu.

O exame do percurso das práticas da Assistência Social é prova factual que a mutação para o campo de uma política pública significa ruptura com a cultura dos agentes políticos que operam essa política.

O terceiro setor vem se destacando por desenvolver um trabalho complementar ao Estado, tentando suprir o que o mesmo tem dificuldades. Santos (2007) cita em seu estudo uma pesquisa em que no total identificou 276 mil organizações do terceiro setor, incluindo desde entidades de ensino superior e hospitais até entidades religiosas, ou seja, instituições constituídas formalmente que possuem o Cadastro Nacional de Pessoa Jurídica, um crescimento de 300\%, passando de 11 mil para 45 mil entidades ${ }^{4}$.

Atualmente existem 290.692 fundações e associações sem fins lucrativos. As áreas de atuação são: 30,1\%, defesa de direitos e interesses dos cidadãos; $28,5 \%$, religiosas; $12,7 \%$, cultura e recreação; 10,5\%, Assistência Social. Outro dado importante é que existem atualmente 2,1 milhões de pessoas com carteira assinada nas fundações e nas associações sem fins lucrativos, o que equivale a $4,9 \%$ dos trabalhadores brasileiros ${ }^{5}$.

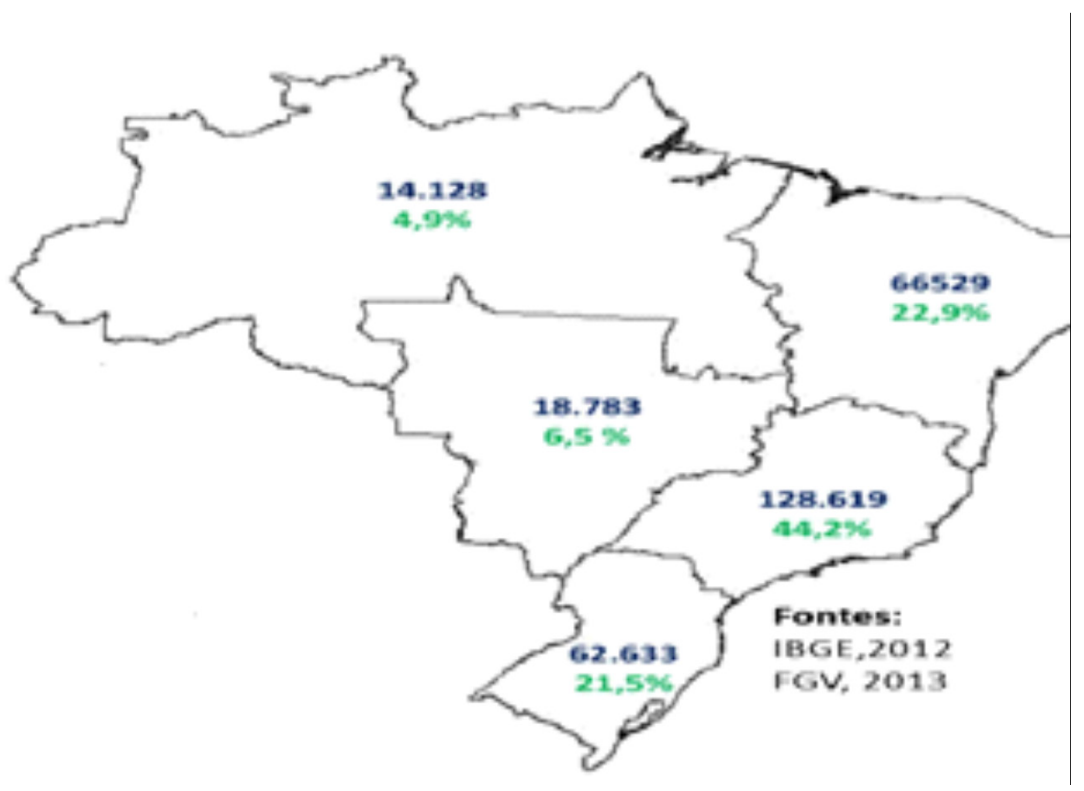

O controle social não funciona como é proposto, não há pressão ou cobrança efetiva para que o Estado cumpra devidamente sua função. Percebe-se então um crescimento permanente de entidades, organizações sem fins lucrativos que prestam serviços voltados não só à Assistência Social, mas à cultura, à educação, à saúde, suprindo espaços que o Estado tem negligenciado. Debatendo com Raichelis (2006, p.112), “o papel da sociedade civil deve ser atuar para ampliar a participação no conjunto das políticas públicas, na sua formulação e gestão, sem que o Estado abra mão de suas responsabilidades”.

4 Pesquisa realizada entre os anos de 1996 a 2002 pelo Instituto Brasileiro de Geografia e Estatística (IBGE) em parceria com o Instituto de Pesquisa Econômica Aplicada (IPEA), Associação Brasileira de Organizações Não Governamentais (ABONG) e Grupo de Institutos, Fundações e Empresas (GIFE).

5 Segundo dados do IBGE (2012) e FGV (2013). 
O Estado estabelece ou terceiriza os serviços das entidades do terceiro setor para desenvolver funções a ele atribuídas. Para Montano (2007), o Estado, ao estabelecer parceria com determinada entidade e não com outra, ao financiar uma, e não outra, ou ao destinar recursos a um projeto, e não a outro, está desenvolvendo uma tarefa seletiva, dentro e a partir de uma política governamental, o que leva tendenciosamente à presença e à permanência de certas ONG's e não outras, e determinados projetos e não outros, sendo selecionados pelos interesses do governo.

O Estado transfere a responsabilidade mediante convênio por mera negligência, não abrangendo o caráter da totalidade, gerando inconformidade, onde deveria haver um enfrentamento adequado com caráter político.

De acordo com a NOB-SUAS (2012),

[...] a nova relação público e privado deve ser regulada, tendo em vista a definição dos serviços de proteção básica e especial, a qualidade e o custo dos serviços, além de padrões e critérios de edificação. Neste contexto, as entidades prestadoras de assistência social integram o Sistema Único de Assistência Social, não só como prestadoras complementares de serviços socioassistenciais, mas como co-gestoras através dos conselhos de assistência social e co-responsáveis na luta pela garantia dos direitos sociais em garantir direitos dos usuários da assistência social. (CNAS, 2012).

As entidades podem celebrar com o Poder Público contrato, contrato de gestão, convênio, termo de parceria, termo de credenciamento, instrumentos que regem direitos e obrigações das partes. Os atores sociais envolvidos agem e se organizam com regras e práticas que são socialmente construídas, previstas e aceitas, assim sendo, a prática de qualquer política deve ter o apoio de todos os atores, para que as decisões sejam tomadas, alterando as percepções dos atores que devem ter meios e interesses no alcance dos objetivos da política executada.

\section{RELAÇÕES DE PODER: PRÁTICA NAS POLÍTICAS E NAS POLÍTICAS PÚBLICAS}

O Estado exerce o poder, formulando as legislações, apropriando-se em tese das riquezas em prol da ordem e do bem comum. Como instância de formulação de leis, o Estado prescreve a ordem e apresentando-se a sociedade como postulado da legalidade, o poder se exerceria por meio da lei.

Um exemplo emblemático seria a política de Assistência Social expressa pela Constituição Federal como dever do Estado e direito do cidadão, cujas demais normativas legitimam a autonomia do Estado como formulador da política. Pelas diretrizes do Sistema Único de Assistência Social na Norma Operacional Básica (2012) o Estado tem a primazia da responsabilidade na condução da política de Assistência Social, e, ainda, cabe a ele coordenar as normas gerais. Já a execução das ofertas poderá ser realizada pelas esferas estaduais e municipais, bem como pelas entidades beneficentes de Assistência Social, garantindo o comando único das ações em cada esfera de governo [...] (CNAS, 2012). Assim, vale a pena dialogar com Foucault (1984), já que para o autor é por meio do postulado da lei que "o poder estaria localizado, no próprio aparelho do Estado, e o poder privado seria proveniente desse aparelho” (p. 46).

O Estado, por ter a primazia da responsabilidade na condução da política, tem no ordenamento jurídico a garantia de que a execução pelos entes estaduais e municipais, bem como pelas organizações da sociedade civil, será conforme o que foi por ele regulamentado, limitando toda 
iniciativa dos executores. Este cenário pode ser apreendido mais uma vez pela lógica foucaultiana, que afirma que o poder é possuído por pessoas ou por instituições, e há uma divisão entre os que possuem e os que são alijados.

A concretização dos direitos é apresentada nas leis de um país, os quais são efetivados através de políticas públicas. Por ser o formulador da lei, o Estado em todas as épocas representa o poder, seja para o bem comum ou o privilégio de uma parcela da população. Foucault (1988, p.83 apud SILVEIRA, 2005) argumenta que "os novos mecanismos de poder funcionam não pelo direito, mas pela técnica, não pela lei, mas pela normatização, não pelo castigo, mas pelo controle e que se exercem em níveis e formas que extravasam do Estado e de seus aparelhos", afirmando que o Estado não só reprime, mas também cria técnicas de aceitação pela sociedade, atendendo seus desejos, uma vez que não dá conta da dinâmica do poder como se exerce de fato.

A política e as políticas públicas estão relacionadas com o poder social, sendo a política pública uma das técnicas referidas por Foucault. Ela é pensada a partir de uma demanda e é voltada para intervenção social, objetivando resultados e impactos à transformação da condição social da população envolvida. É delineada a partir de planos e programas de ação governamental ou da sociedade civil, traçada a partir de legislações e normas já decretadas e fomentadas pelo Estado, tendo metas e diretrizes socialmente relevantes e politicamente organizadas.

No que diz respeito ao objeto aqui estudado, por ser a política pública uma atividade que vem para sanar o problema de determinada sociedade, permitindo a eficiência e a eficácia de uma dada prática social, seria ela "uma atividade concentrada pela instituição do poder, processo de construção de uma ordem” (SOUZA, 2007 apud DIAS; MATOS, p.3, grifo nosso).

Os pontos de vistas divergentes e os interesses diferentes dos atores envolvidos devem ser relacionados na tomada de decisão para implantação de políticas públicas, de forma a conciliar as escolhas em uma determinada ação. Conforme as palavras dos autores:

No contexto das políticas públicas, a política deve ser entendida como um conjunto de procedimentos que expressam relações de poder. Estes por sua vez, se orientam para solução de conflitos no que se refere aos bens públicos. A política implica a possibilidade de se resolverem conflitos de forma pacífica. (SCHIMITTER, 1984 apud DIAS; MATOS, 2012, p.3).

Dialogando com estas reflexões, entende-se o poder como elemento básico na implementação de toda política pública. Não o poder em sua forma unilateral, mas em termos de relações de poder, pois como diz Foucault, não existe o poder, mas feixe de relações de poder, mais ou menos organizadas, piramidalizadas, coordenadas.

O poder é uma prática social constituída historicamente, associada a práticas de dominação, dimensão humana criativa e indefinida, assim diz Bartolomé Ruiz (apud SOUZA, 2011, p. 104). As relações de poder não são entendidas apenas como propriedade de grupos ou classes da exploração econômica, mas das relações que nos constituem como sujeito.

Para o autor, a questão do poder não é apenas teórica, faz parte da nossa experiência e será mais bem compreendida quando analisada dentro de um contexto, pois o poder não é unitário, é heterogêneo e mutante, constitui-se numa prática social.

No cofinanciamento das entidades privadas o poder se dissemina, seja por meio das normas do poder público ou pelo serviço não governamental por meio de um poder disciplinar, pela atenção ao indivíduo dentro de seu espaço, de sua condição social. 
O poder está atrelado ao saber, pois não há saber neutro, o saber tem sua origem no espaço em que atuam as relações de poder, é político. Toda constituição do saber estará associada ao exercício de um poder, assim, o indivíduo é produto do poder. "[ [...] é o saber enquanto tal que se encontra dotado estatuariamente, institucionalmente, de determinado poder. O poder funciona na sociedade dotado de poder. É enquanto é saber que tem poder". (FOUCAULT, 1984, p.22).

Mas o Estado não é o único detentor do saber, assim, não congrega todas as formas nas relações de poder. Na análise de Foucault e conforme exemplos das relações sociais já mencionadas, existem ponto periféricos, extremidades sociais, como instituições, famílias, igreja, escola, os quais intensificam as relações de poder existentes, conforme esclarece Machado (1987 apud SOUZA, 2011, p. 108) "Não se tratava porém de minimizar o papel do Estado nas relações de poder existentes em determinada sociedade. O que se pretendia era se insurgir contra a ideia de que o Estado seria o órgão central e único do poder, [...]”.

Não se trata de eliminar o poder central que o Estado adquiriu, mas de entender que também as organizações refletem e reproduzem relações sociais e consequentemente relações de poder e, sobretudo, de entender que "não estão localizados em nenhum ponto específico da estrutura social. Funcionam como uma rede de dispositivos ou mecanismos a que nada ou ninguém escapa, a que não existe exterior possível, limites ou fronteiras” (FOUCAULT, 1984, p.18)

Assim sendo, não existe o poder centralizado no Estado ou em uma organização, mas relações de poder que se exerce e se efetiva nas relações sociais de força, como no caso da relação entre a rede socioassistencial privada e na relação entidade, usuário e suas famílias.

Um dos aspectos que torna o Estado ou as organizações públicas o centro das relações de poder, distinguindo das organizações privadas, é que muitas das políticas públicas, conforme sua classificação, se instalam com aspecto coercitivo oficializado pelo Estado, aceitas pelos cidadãos como legítimas. Como é o caso das políticas constitutivas que devem ser obedecidas como normas que regulam o funcionamento, aqueles que não o fizerem ou não participam do processo serão penalizados.

Ao se analisar e estudar a sistematização da relação público privado na rede socioassistencial é preciso entender que a partir do momento que as instituições agem por meio de regras e leis, as obrigações das parcerias se tornam mecanismos que, ao mesmo tempo, garantirão o custeio parcial das despesas dos serviços para as entidades e para o poder público, ainda que de forma indireta exerce sua função, se constituindo e constituindo o campo próprio a uma relação de poder, sendo ações que se inter-relacionam pelos mesmos objetivos.

Por esta análise das formas institucionalizadas das relações de poder se formam sistemas complexos, mas não se pode olvidar que o Estado é a instância de controle global por ter o princípio de regulação, distribuir e agregar todas as formas de relações sociais dentro do conjunto social.

\section{Considerações finais}

Quando o Estado assume seu dever, ainda assim suas responsabilidades ainda são significativas pela prestação de serviços com a participação das organizações privadas. Mas não é clara a relação entre o Estado e a sociedade civil, por isto tal relação é complexa, o que acaba subordinando a benesse do setor privado ao dever dos entes federados.

O Estado, como uma associação política em prol do bem comum, tem a função de prover serviços públicos, executando ações consideradas de interesse público. 
Qualquer política pública deve ser confeccionada ou executada pelo Estado, pois ele tem a primazia da responsabilidade na efetivação dos direitos sociais, por meio da implantação de políticas públicas, criadas e coordenadas pelo Estado, que não podem ser exercidas nem pelo mercado nem pela sociedade civil.

O Estado deve, de fato, desempenhar o papel central de regulamentação, direção, coordenação, incentivos e parte substancial do financiamento das políticas sociais públicas. Uma vez que tem a centralidade na regulação das mesmas, é o Estado quem referencia às provisões e às proteções sociais.

As parcerias antes firmadas por meio de relações tradicionais entre o Estado e a sociedade civil organizada estão sendo modificadas substancialmente, passando por um processo de reestruturação devido ao marco regulatório.

Tais fatores trazem tensões e desafios que vão além da implantação da política pública e se remetem às relações sociais mais amplas, constituídas historicamente. Nas relações de poder que se exercem com invisibilidade por meio do saber, registram e transferem o domínio de ações sobre ações, como uma matriz geral de forças através de rede de dispositivos e mecanismos que atravessam toda a sociedade.

O requisito para o avanço de um sistema único normativo é fortalecer o diálogo entre os atores, promovendo a participação da sociedade civil e respeitando os saberes num processo de interlocução e pactuação, que deve ser de responsabilidade e de iniciativa do Estado, uma vez que a consolidação da Assistência Social como política pública incita a busca de consenso que consolide o caráter público de ofertas qualificadas e processos de trabalhos realizados de forma equânime a toda a rede.

O Estado precisa fortalecer e articular a rede socioassistencial, democratizando sua forma de participação em todas as etapas de construção da política pública, redefinindo estratégias para o processo de inclusão social na realidade do município, reafirmando a garantia de direitos socioassistenciais.

\section{REFERÊNCIAS}

Augusto, M. H. O. Políticas públicas, políticas sociais e política de saúde: algumas questões para reflexão e debate. Tempo Social; Rev. Sociol. USP, S. Paulo, 1(2): 105-119, 2.sem 1989.

BONFIM, P. Entre o público e o privado: as estratégias atuais no enfrentamento à questão social. Revista katálysis. Florianópolis. V. 13, n.2 p.270-275, jul./dez. 2010.

BRANDÃO, F. A. Políticas Públicas: O financiamento Público da Assistência Social. 2012.

BRASIL. Constituição da República Federativa do Brasil. 1988.

BRASIL. Lei $N^{\circ}$ 8742/1993 alterada pela Lei $N^{o}$ 12435/2011. Dispõem sobre a organização da assistência social.

CNAS. Conselho Nacional de Assistência Social. Resolução No 33 de 12 de dezembro de 2012. Aprova a Norma Operacional Básica do Sistema Único de Assistência Social -NOB/SUAS.

CNAS. Conselho Nacional de Assistência Social. Resolução No 145 de 15 de outubro de 2004. Política Nacional de Assistência Social. 
70 - RBTS - v.3, n. 1,2016

CNAS. Conselho Nacional de Assistência Social. Resolução $N^{\circ} 14$ de 15 de maio de 2014. Define os parâmetros nacionais para a inscrição das entidades ou organizações de Assistência Social, bem como dos serviços, programas, projetos e benefícios socioassistenciais nos Conselhos de Assistência Social.

DIAS, T.; CARIO, S. A. F. Sociedade, desenvolvimento e o papel estratégico do Estado: uma reflexão sobre o surgimento da Governança Pública. Ensaios FEE, Porto Alegre, v.35, n.2, p.337-362, dez, 2014.

DIAS, T.; CARIO, S. A. F. Governança Pública: um ensaio da gênese do movimento que coloca o Estado voltado para a perspectiva paraeconômica de desenvolvimento. ANPAD. SALVADOR/ Bahia, 18 a 20 de novembro de 2012.

FOUCAULT, M. Microfísica do poder. 4.ed. Rio de Janeiro: Edições Graal, 1984.

HOWLETT, M.; RASMESH, M.; PERL, A. Política Pública seus ciclos e subsistemas: uma abordagem integral. Rio de Janeiro: Elseivier, 2013.

MONTAÑO, C. Terceiro Setor e questão social: crítica ao padrão emergente de intervenção social. 4.ed. São Paulo: Cortez, 2007.

PAES, J. E. S. Fundações e entidades de interesse social: aspectos jurídicos, administrativos, contábeis e tributários. 4.ed. Brasília: Brasília Jurídica, 2000.

PFEIFER, M. O “social” no interior do projeto neodesenvolvimentista. Serviço Social e Sociedade. São Paulo, n.120, p.746-766, out/dez. 2014.

SECCHI, L. Política pública: Conceitos, Esquemas de análise, casos práticos. São Paulo: Cengage Learniing, 2012.

SILVEIRA, R. A. da. Michel Foucault: Poder e análise das Organizações. Rio de Janeiro: FGV, 2005.

SNAS. Secretaria Nacional de Assistência Social . Capacita Suas. Desafios da Gestão do SUAS nos Municípios e Estados / Ministério do Desenvolvimento Social e Combate à Fome, Instituto de Estudos Especiais da Pontifícia Universidade Católica de São Paulo - 1 ed. - Brasília: MDS, 2008.

SOARES, L. E. Uma interpretação do Brasil para contextualizar a Violência. 200o. In: PEREIRA, C. A. M. et al. Linguagens da Violência. Rio de Janeiro: Rocco, 2000.

SOUSA, P. I. de; COURA, A. de C. Controle Judicial de Políticas Públicas. 2008.

SOUZA, W. L. Ensaio sobre a noção de poder em Michel Foucault. Revista Múltiplas Leituras, v.4, 2011.

VIANNA, M. L. T. W. Em torno do conceito de política social: Notas Introdutórias. Rio de Janeiro, 2002. 